\title{
El hombre y su representación en Lincoln (Steven Spielberg, 2012): un análisis textual
}

\author{
José DÍAZ-Cuesta \\ Universidad de La Rioja (España) \\ jose.diaz-cuesta@unirioja.es
}

\begin{abstract}
Resumen
Este artículo se centra en la representación de masculinidades en el texto fílmico Lincoln (Spielberg, 2012), siguiendo los cuatro entornos definidos por Pat Kirkham y Janet Thumim para su estudio en obras cinematográficas: el cuerpo, la acción, el mundo externo y el mundo interno. El análisis textual realizado revela que el uso de la palabra e incluso su ausencia atraviesan esos cuatro emplazamientos, marcando al personaje interpretado por Daniel Day-Lewis.
\end{abstract}

Palabras clave: Lincoln, Steven Spielberg, masculinidades, análisis textual, Abraham Lincoln.

\section{Man and his representation in Lincoln (Steven Spielberg, 2012): a textual analysis}

\begin{abstract}
This journal article centres on the representation of masculinities in the film text Lincoln (Spielberg, 2012), following the four sites Pat Kirkham and Janet Thumim define for the study of masculinities in film: the body, action, the external world and the internal world (1993: 11). The textual analysis reveals that the use of the word and even its absence run through those four sites, defining the character performed by Daniel Day-Lewis.
\end{abstract}

Key Words: Lincoln, Steven Spielberg, masculinities, textual analysis, Abraham Lincoln.

Referencia normalizada:

Díaz Cuesta, J. (2013) El hombre y su representación en Lincoln (Steven Spielberg, 2012): un análisis textual. Historia y Comunicación Social. Vol. 18. Nº Especial Diciembre. Págs. 653-666.

Sumario: 1. Introducción; 2. Metodología; 3. Análisis textual; 3.1. The body; 3.2. Action; 3.3. The external world, 3.4. The internal world; 4. Síntesis y conclusiones finales; 5 . Referencias bibliográficas.

\section{Introducción ${ }^{1}$}

A pesar de lo mucho que se ha escrito sobre Steven Spielberg y su obra, existen pocos estudios académicos dedicados a este autor, como recordamos en Díaz-Cuesta (2012: 273-274): limitándonos a los idiomas inglés y español, contamos con Antonio Sánchez-Escalonilla (1995 y 2004), Yosefa Loshitzky (1997), Charles Silet (2002), David Caldevilla (2005), Warren Buckland (2006), Lester Friedman (2006), Nigel Morris (2007), Andrew Gordon (2008), Dean Kowalski (2008), José Díaz-Cuesta (2010) y Frederick Wasser (2010). 
Continuamos aquí el camino iniciado en Díaz-Cuesta (2010 y 2012), pasando del género de monstruos al género que podríamos catalogar como histórico, en ampliación de la tipología de obras de Spielberg propuesta por Friedman (2006) a lo largo de su monografía. Tanto Amistad (Spielberg, 1997) como Lincoln (2012) entrarían dentro de este nuevo tipo, situándose más allá del melodrama (Torres-Hortelano, 2011: 62).

Como en nuestros análisis anteriores, lo que nos ocupa principalmente es la representación de masculinidades en la película que hemos escogido. El hombre y su representación constituyen nuestro principal foco de atención. No se trata de analizar al "vencedor de la guerra de Secesión" (Brufao García, 1997: 51), sino al hombre que hay tras el mismo.

\section{Metodología}

A continuación procedemos a realizar un análisis textual que explora los cuatro sites o entornos propuestos por Pat Kirkham y Janet Thumin (1993: 11) como definitorios de las masculinidades en películas cinematográficas: "the body, action, the external world and the internal world" (Kirkham y Thumim, 1993: 11).

Finalmente realizamos una síntesis de la exploración realizada, de tal manera que nuestro método es analítico-sintético. Este método ha sido utilizado previamente en Díaz-Cuesta (2010 y 2012).

\section{Análisis textual}

Cada uno de los siguientes sub-apartados está dedicado a uno de los entornos contemplados por Kirkham y Thumim.

\subsection{The Body}

La star persona es lo primero que tienen en cuenta Kirkham y Thumim: Daniel Day-Lewis es el actor con el papel de protagonista absoluto del film. Repasar su carrera supone recorrer una lista de interpretaciones difíciles de olvidar, como la ofrecida en My Beautiful Laundrette (Frears, 1985), o sobre todo en My Left Foot (Sheridan, 1989) como Christy Brown - película basada en hechos reales, al igual que Lincoln - The Last of the Mohicans (Mann, 1992), In the Name of the Father (Sheridan, 1993) — como Gerry Conlon—, The Age of Innocence (Scorsese, 1993), o There Will Be Blood (Anderson, 2007), por citar algunas de sus obras más destacadas.

Con Lincoln gana su tercer Óscar este actor que no se separa de sus personajes en ningún momento durante todas las semanas que dure la filmación, y a quien le resulta difícil separarse del personaje tras el rodaje, como él mismo reconoce: 
There's a terrible sadness. The last day of shooting is surreal. Your mind, your body, your spirit are not in any way prepared to accept that this experience is coming to an end. In the months that follow the finish of a film, you feel profound emptiness. You've devoted so much of your time to unleashing, in an unconscious way, some sort of spiritual turmoil, and even if it's uncomfortable, no part of you wishes to leave that character behind. The sense of bereavement is such that it can take years before you can put it to rest. ${ }^{2}$

\section{Y añade Day-Lewis:}

I miss playing Lincoln. Very much. I miss the proximity to his character. There was a time in my life when it wasn't clear whether or not I would amount to anything. I was fearful about my future. In England, people were hell-bent on certifying me -- to them, the way I work as an actor is the system of someone who is unhinged. As a young man, when I saw the early movies by Martin Scorsese, I saw a way to be, a kind of liberation. In those movies, America seemed like a place of infinite opportunities. In Lincoln (2012), we tried to show that sense of grand democratic possibility. We created a world I didn't want to leave. ${ }^{3}$

Esa renuncia a abandonar sus personajes ha marcado la trayectoria de este actor. Él mismo ha reconocido que envejeció haciendo esta película.

En segundo lugar, dentro del entorno del cuerpo, Kirkham y Thumim se centran en la mostración que se realiza en la película de la fisonomía de cada personaje masculino, principalmente en papeles protagónicos.

Resulta de especial importancia la primera aparición en escena de ese personaje, como lo es la primera impresión que recibimos de un desconocido en nuestras propias vidas.

Lo primero que nos llega del Lincoln de Spielberg es su voz, en off, mientras

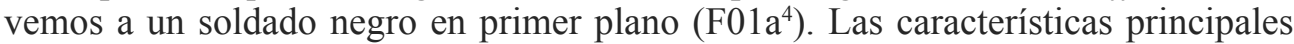
del presidente — su voz y su elocuencia — están presentes en esta primera aparición de Lincoln en el texto fílmico. La cámara se mueve hacia atrás para dejarnos ver, sin cambiar de toma, parte del cuerpo del presidente.

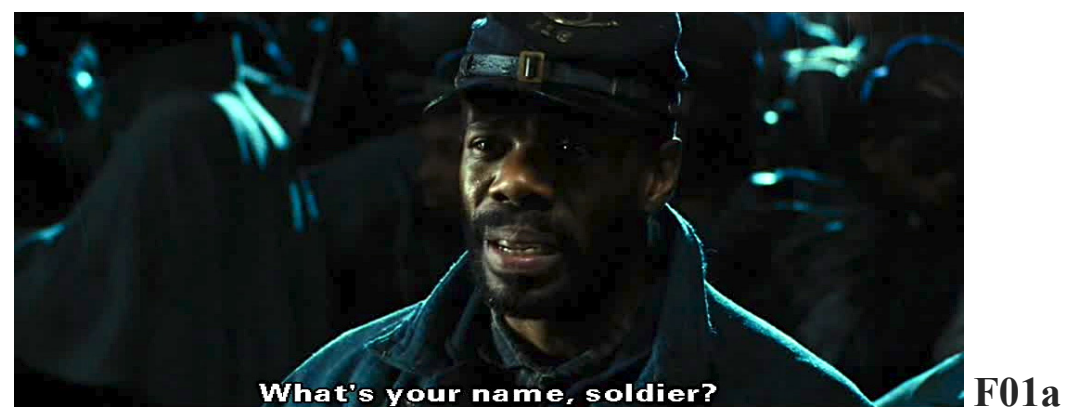




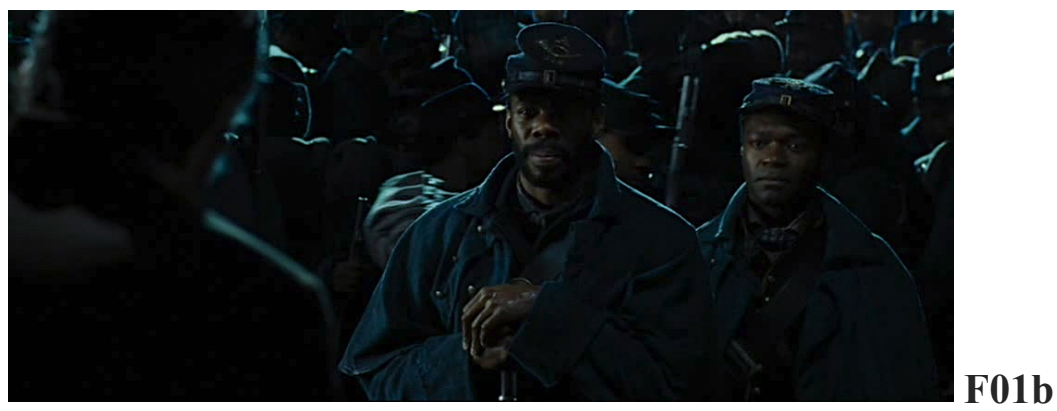

En el contraplano observamos que Lincoln está sentado (F02), tal vez aludiendo al Lincoln Memorial, que se erigió en un recuerdo de la infancia de Spielberg cuando lo vio por primera vez (Schickel, 2012: 265).
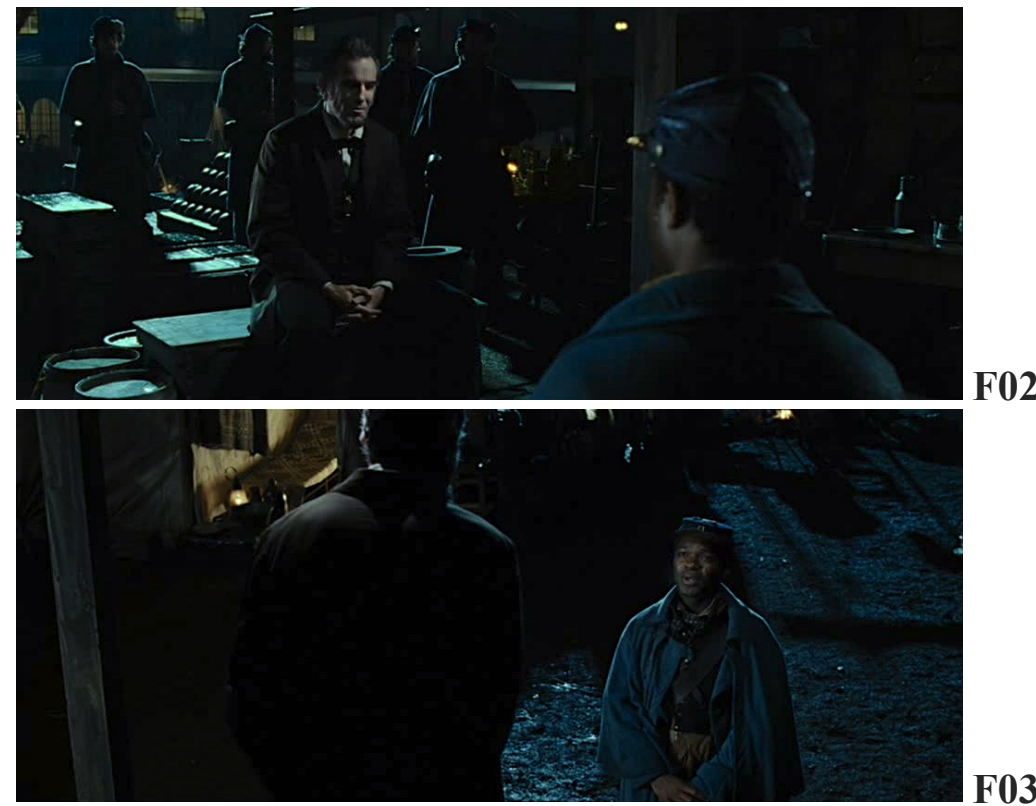

Poco después, con el presidente de pie, lo que convierte el plano en más picado que el primero (F03), el soldado del principio cita literalmente un discurso de Lincoln. La importancia de la palabra queda subrayada con este gesto

Volvemos al cuerpo del presidente en un sueño. La representación adquiere un carácter fantasmagórico (F04): Spielberg invoca al espíritu de Lincoln para que los espectadores creamos que quien habita las diferentes escenas de la película es su espectro, y que no se trata del actor Daniel Day-Lewis. 


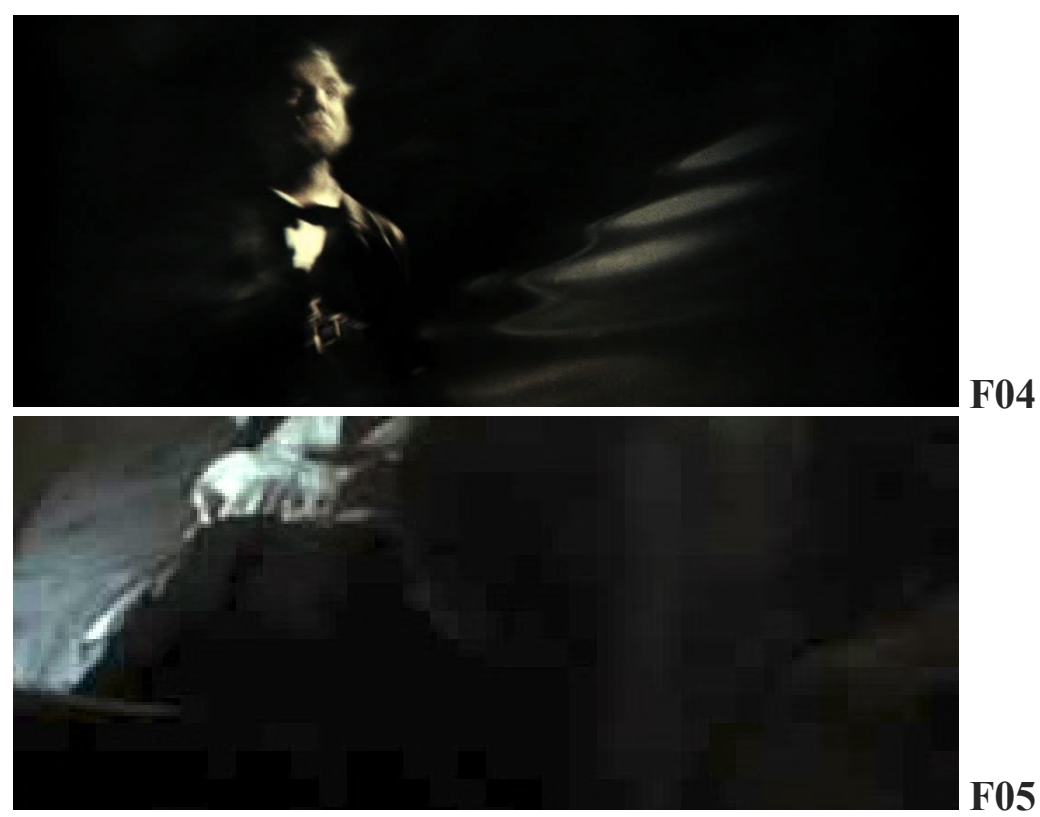

A continuación descubrimos que su cuerpo, desde el que ha recordado el sueño, está descansando en el dormitorio presidencial (F05).

En otra ocasión es posible verlo andando a cuatro patas, dedicado a la tarea doméstica de avivar el fuego (F06), en una muestra de que también se preocupa por lo más básico, no solo por la integridad de su país.

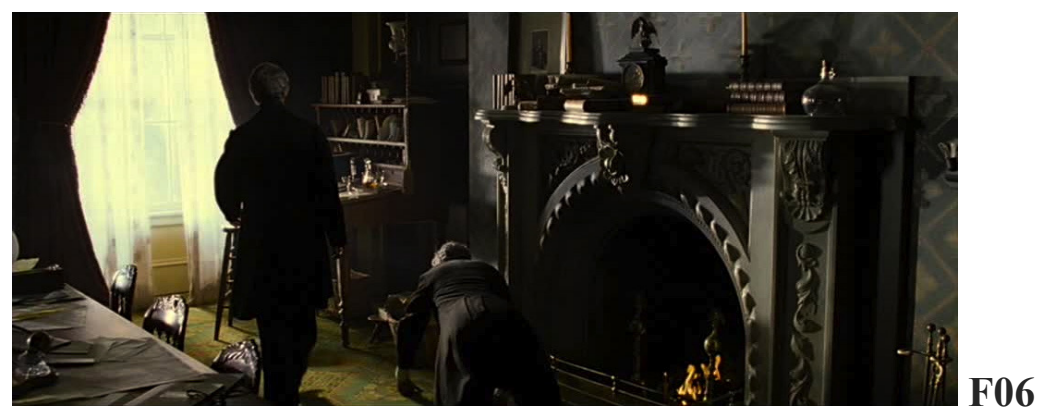

\subsection{Action}

Según Kirkham y Thumim, la acción se caracteriza por "various representations of the physical, including violence, competition, aggression, skill and endurance, in which these attributes are depicted in terms of the male body in action" (Kirkham y Thumim, 1993: 12). 
Observamos cuerpos de hombres en acción tras el intertítulo "AND THE WAR CAME". La toma es general (F07a), no demasiado alejada, sin que podamos identificar a los luchadores, ni siquiera el bando por el que luchan, por el barro y el agua que los envuelven: un vivo exponente de lo que está sucediendo: la guerra entre compatriotas. La presencia de la bandera estadounidense, portada por un soldado negro (F07b), marca la línea divisoria entre ambos bandos.

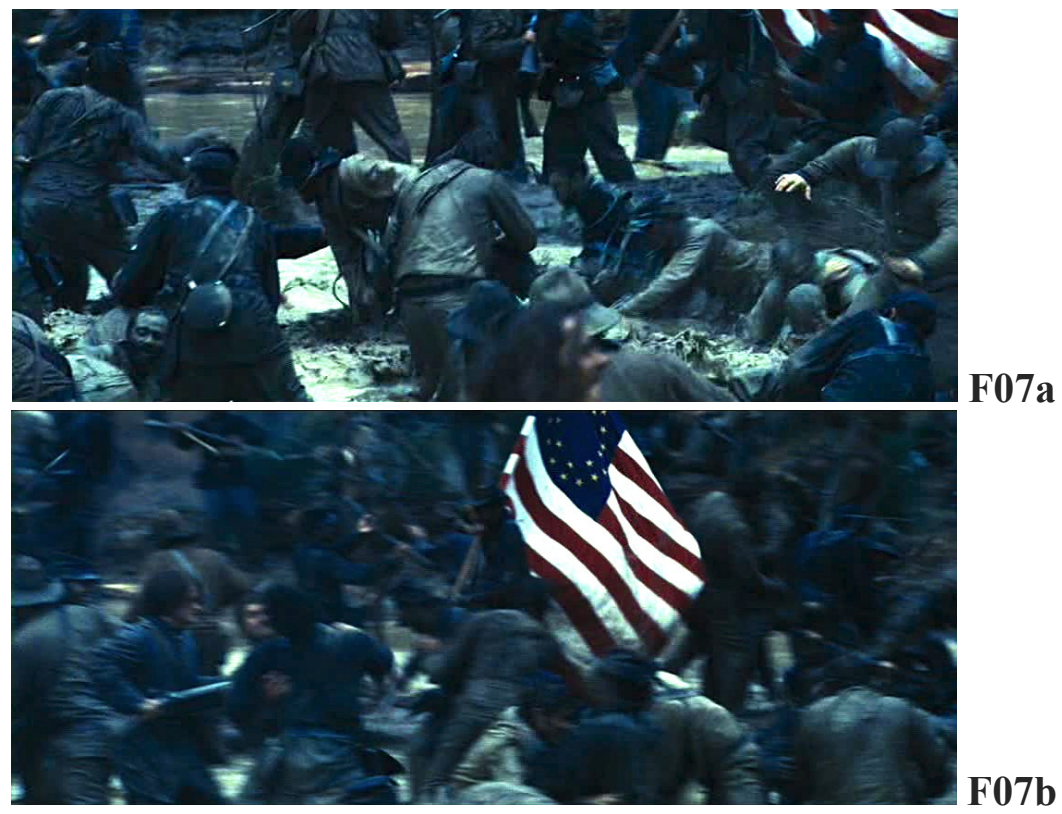

La virulencia del enfrentamiento se expone en un par de tomas: en la primera un soldado de la Unión perfora el pecho de un secesionista con su bayoneta (F08), en la segunda la víctima es un soldado negro del otro bando, atacado por las bayonetas de sus enemigos (F09). En ninguno de los casos se muestra la menor concesión al contrario.

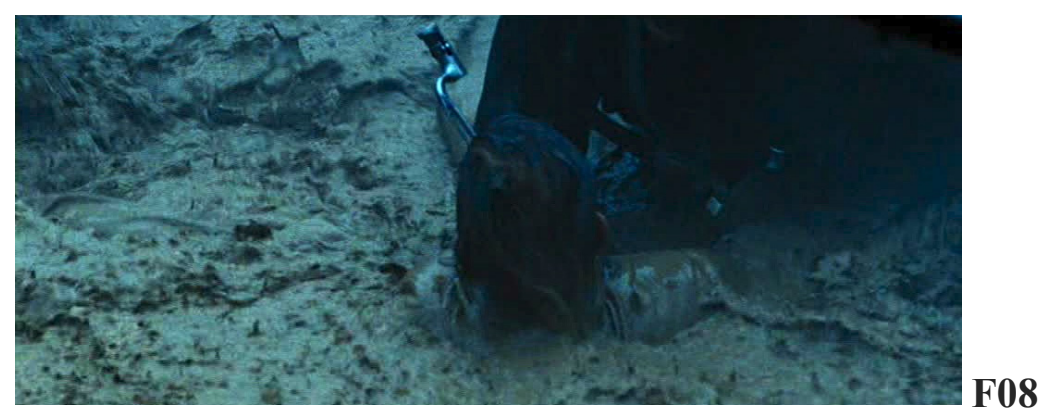




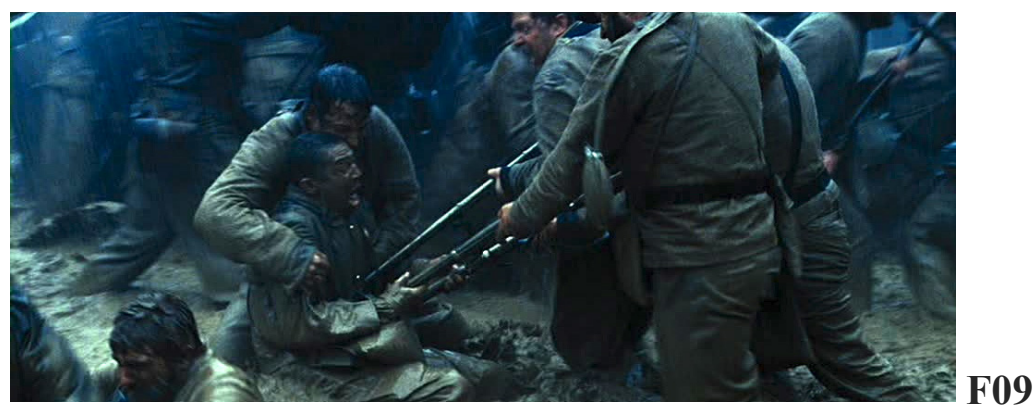

Esta escena de lucha, a pesar de situarse en el arranque del film, es pronto amortiguada por las palabras del soldado negro que se dirige a Lincoln, secuencia a la que nos hemos referido en el entorno del cuerpo. El texto fílmico que nos ocupa es principalmente hablado: son los discursos y los diálogos lo que hacen que la trama se desarrolle, con pocas incursiones en el campo de batalla físico.

Sí somos testigos de algunas de las consecuencias de esa batalla, como cuando se nos muestran cómo son enterrados brazos y piernas (F10), en un plano que nos recuerda a tomas similares en Schindler's List.

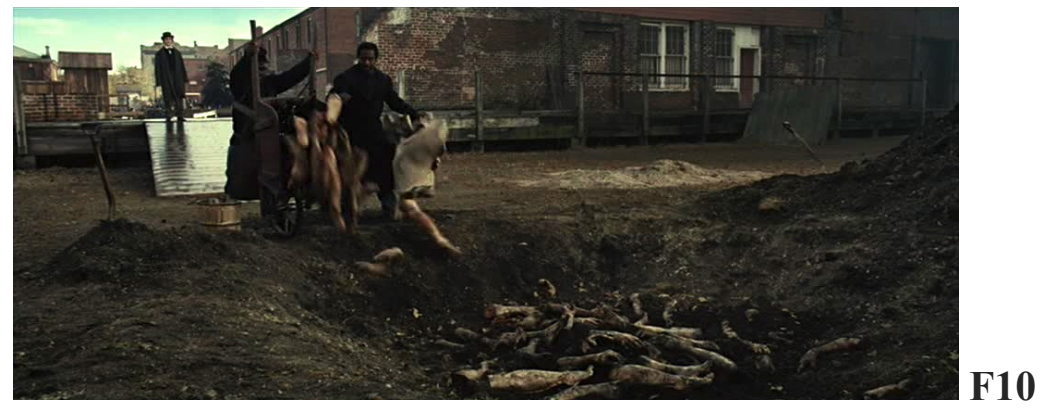

Uno de los últimos campos de batalla es visitado por Lincoln cuando lo único que se puede observar son cadáveres por doquier. El presidente ve todo esto desde su caballo (F11), como lo había hecho Oskar Schindler durante la liquidación del gueto de Varsovia. Pero aquí Lincoln ya había tomado sus decisiones.

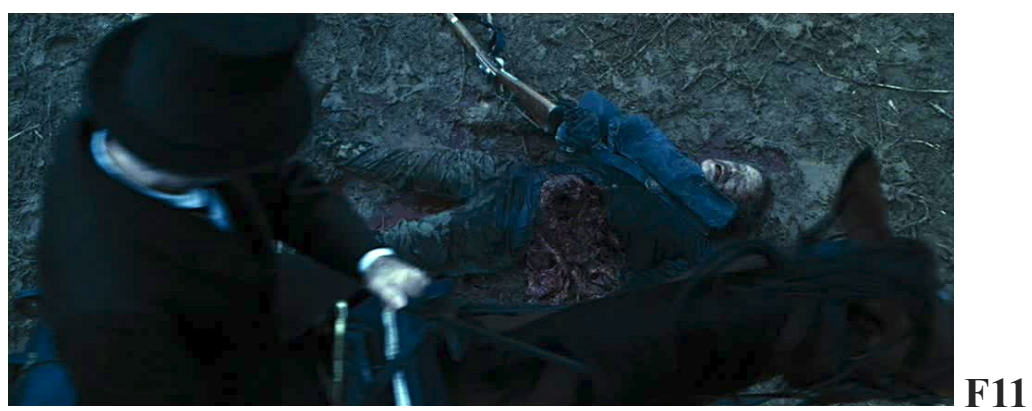


Tras ser conocedores de que el presidente ha sido disparado, se nos brinda acceso a la habitación en la que fallece: ya muerto, la toma transiciona de la imagen del cadáver en su cama (F12a) a otra de un quinqué en el que brilla la luz y la palabra del presidente (F12b).

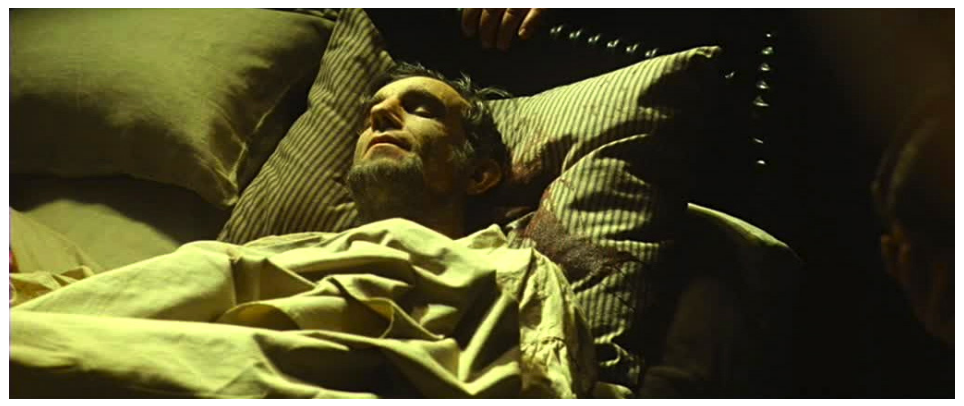

F12a

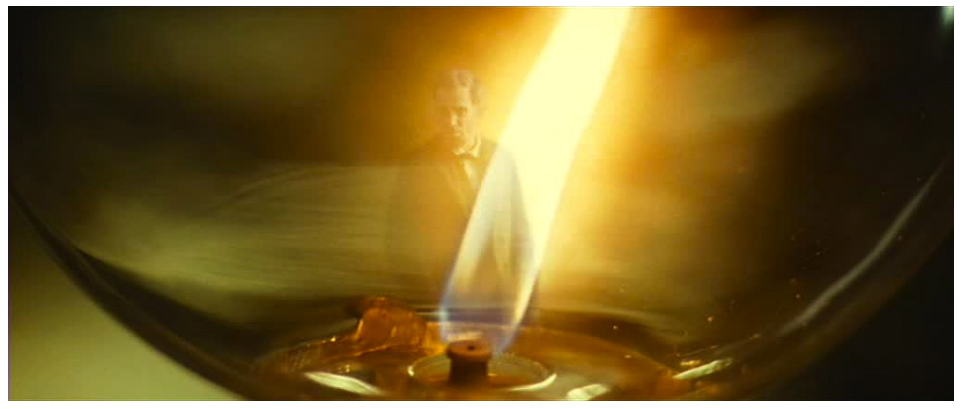

F12b

\subsection{The External World}

"[R]epresentations of the public interactions of male characters with each other and with the conventions and institutions against which they operate": así es como Kirkham y Thumim (1995: 12) resumen las referencias a las masculinidades cinematográficas en el entorno del mundo externo. En este texto fílmico, Lincoln se mueve entre su familia y su Gabinete.

La primera aparición de Mary Todd Lincoln (Sally Field), esposa del presidente, sucede cuando se está relatando el sueño que hemos mencionado al referirnos al cuerpo. Aunque comparten plano, reflejados en un espejo de la estancia (F13), lo que se remarca es la separación que dista entre los esposos. De hecho, en el sueño el marido ha subrayado su sentimiento de aloneness. 

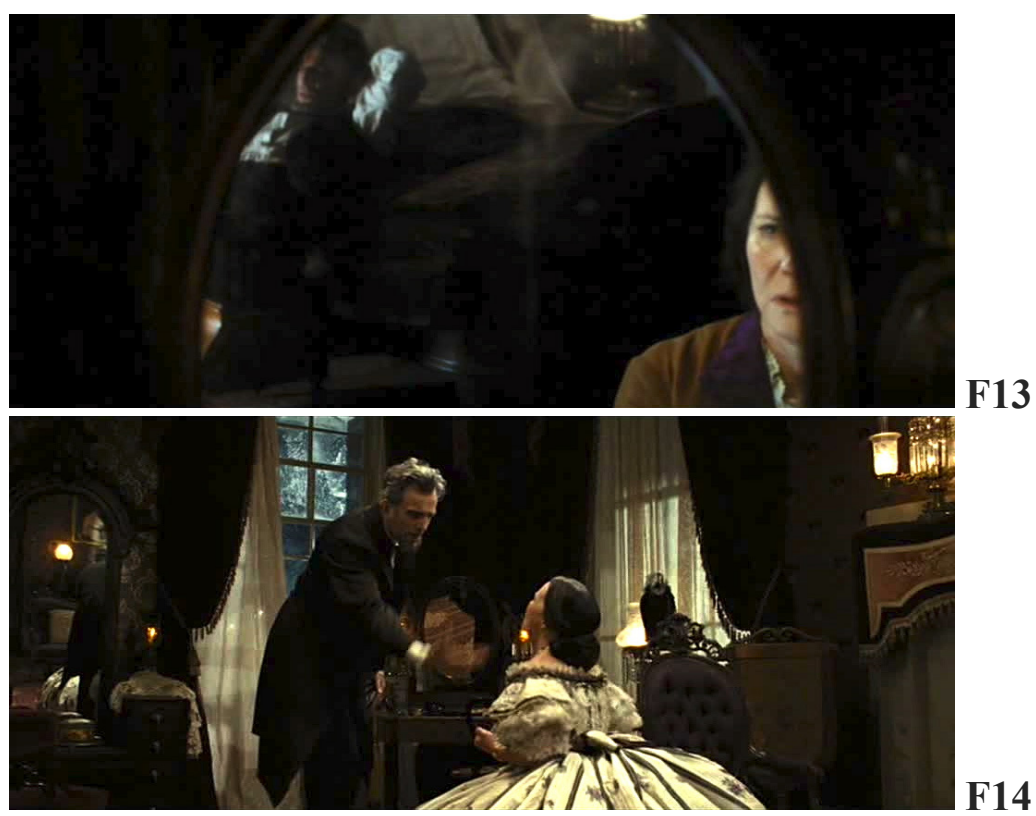

La influencia de la política en la familia se patentiza en el enfrentamiento que tiene la pareja al hablar del hijo mayor, que pretende acudir a la guerra. La conversación deriva hacia otro hijo que falleció, y hacia el sufrimiento que para ambos supuso su pérdida. Mary Todd le recuerda que en aquella ocasión él había intentado recluirla en un manicomio. Abraham subraya una vez más la soledad en la que cada uno se encuentra: separación que se ve plasmada en imágenes (F14).

Los vínculos que el presidente mantiene con los dos hijos que le quedan vivos dependen de la edad de cada uno de ellos. En el caso del más joven, Tad (Gulliver McGrath), podemos observar, por ejemplo, cómo su padre se agacha aquí también a cuatro patas para velar por su sueño (F15): es decir, se sitúa a su mismo nivel.

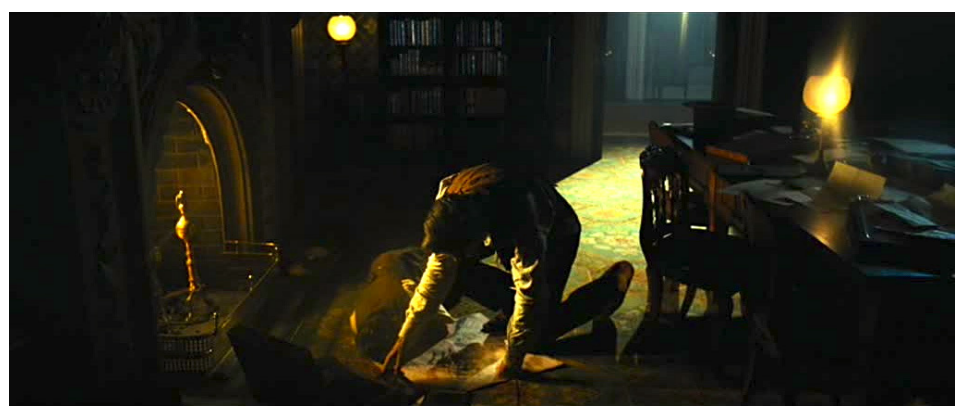




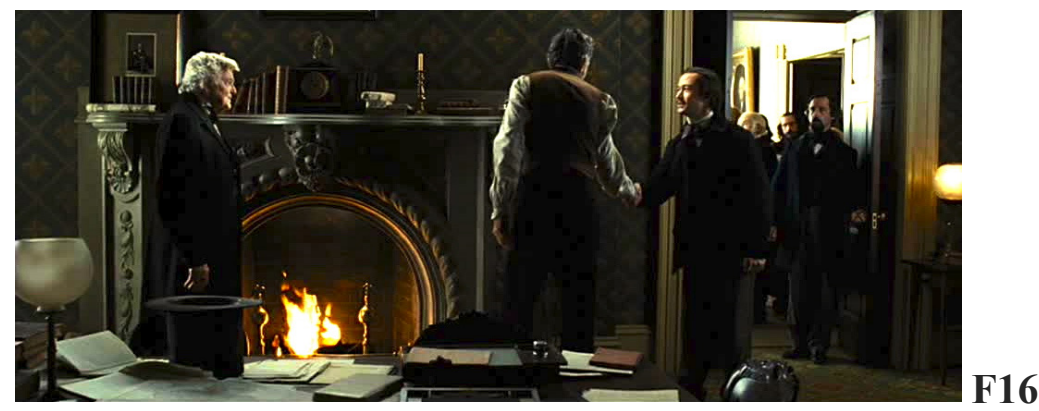

El hijo de más edad, Robert (Joseph Gordon-Levitt), vuelve a casa y es recibido calurosamente por su madre y su hermano, pero no así por su padre, quien tras chocar su mano como si fuera otro político (F16) pospone su encuentro a cuando termine su entrevista de trabajo, en la que precisamente se está hablando del futuro de los descendientes, tanto de aquellos que están luchando como los que están a punto de hacerlo.

La conversación más tensa entre el hijo mayor y el padre sucede cuando el segundo pretende influir sobre el primero para que no combata (F17), mostrándole un hospital en el que Robert acaba observando los restos amputados a los que nos hemos referido anteriormente.

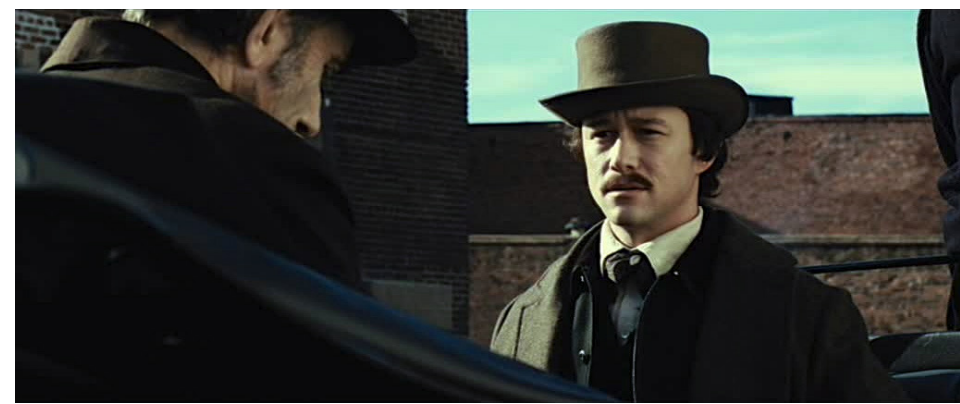

F17

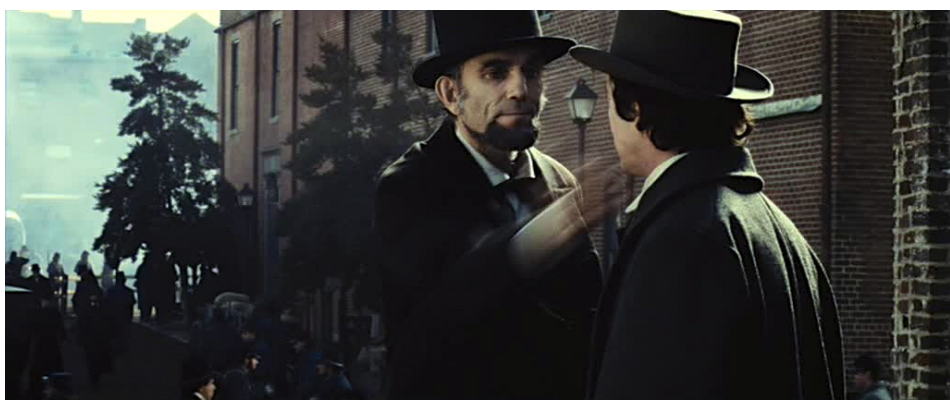

F18 
Cuando el hijo le dice al padre que a quien teme este último es a su esposa, Mary Todd, Lincoln le abofetea (F18): las palabras se le quedan cortas al presidente cuando se trata de afrontar conflictos familiares, $\mathrm{y}$ hace uso de la violencia.

En la relación con su Gabinete, resulta destacable la primera sesión que nos ofrece el texto fílmico. Intervienen varios de sus componentes, según nos muestran distintos planos fijos. Pero para ceder la palabra al presidente, la cámara recorre la sala mientras observamos el efecto de su palabra sobre sus compañeros (F19a y F19b): aquí sí le basta con su discurso.

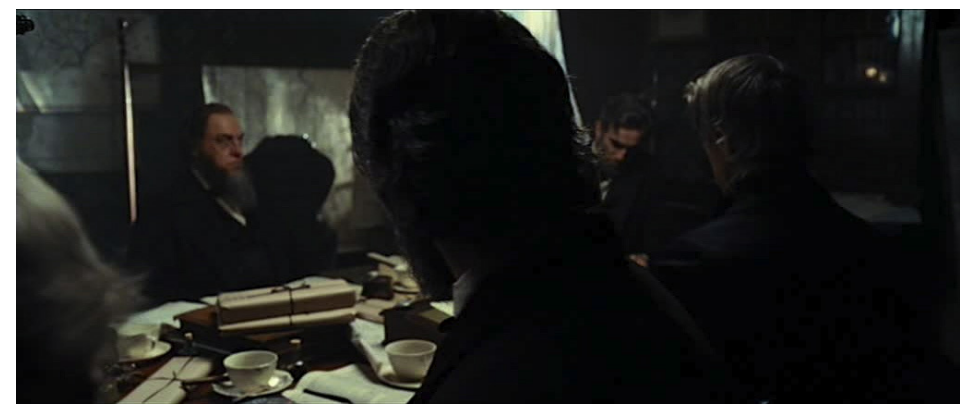

F19a

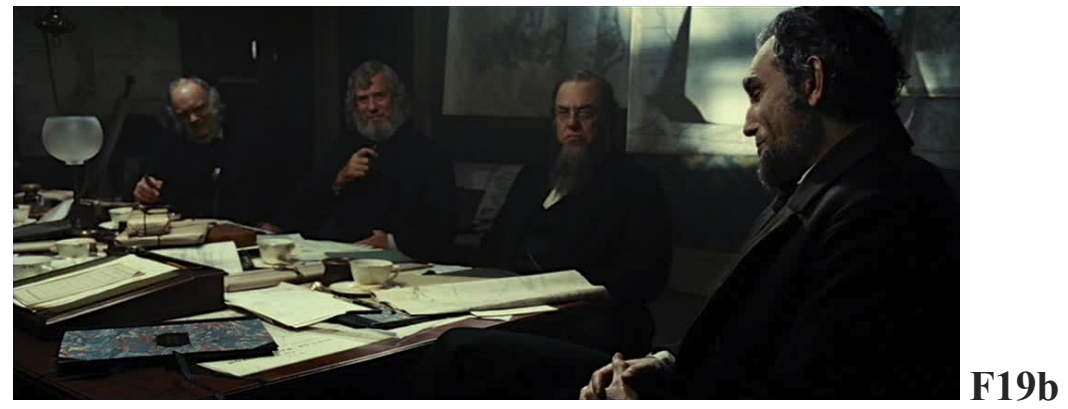

\subsection{The internal world}

Para Kirkham y Thumim, el mundo interno se resume en "the experience and articulation of being, from the inside, as it were" (1993: 12). En esta película esa articulación y esa experiencia se detectan en los sentimientos que suscitan el hijo que se le murió a la pareja y el deseo de erradicar la esclavitud.

El primer sentimiento podríamos haberlo contemplado en el entorno del mundo externo, pero aquí cobra toda su agudeza, ya que se trata de un dolor que, a pesar de su elocuencia, deja a Abraham Lincoln sin palabras: incapaz de verbalizar ese sentimiento, como sí lo hace su esposa, y culpándola a ella por exteriorizar un dolor que demuestra lo difícil que supone enfrentarse a la muerte de un hijo, aunque se trate del del presidente de los Estados Unidos de América.

Derogar el esclavismo parece ser la meta que se ha impuesto el presidente en esta etapa de su vida, que a la postre termina siendo la última, y por la que será siem- 
pre recordado. La película logra que esa pertinacia por aprobar la Decimotercera Enmieda de la Constitución estadounidense se sitúe por encima de la mentira y la extorsión ${ }^{5}$. Al igual que en War of the Worlds (Spielberg, 2005), el director nos sitúa en un camino en el que se abren dos vías: solo desde nuestro interior podremos escoger el que consideremos correcto.

Spielberg, junto con Janusz Kaminski, su director de fotografía, vuelcan esa obcecación en una toma que se aproxima como pocas a la interioridad del presidente. Lo vemos a solas, en una postura sentada, con su cuerpo inclinado sobre una mesa en la que va midiendo cómo pasa el tiempo, dándole golpes a un reloj, acompasadamente, como si fuera un metrónomo (F20). Localizamos el plano cuando se acerca la mitad del texto fílmico. Lincoln ha de ser capaz de gestionar su propio tiempo y los tiempos de sus contrincantes: con su gesto, parece que estuviera controlando ese tiempo, pero lo que en realidad hace es adaptar su mente al devenir de la Historia. La secuencia queda doblemente subrayada por el hecho de que nos muestra una de los pocos instantes, en el transcurso de la película, en el que el presidente no hace uso de su capacidad de hablar.

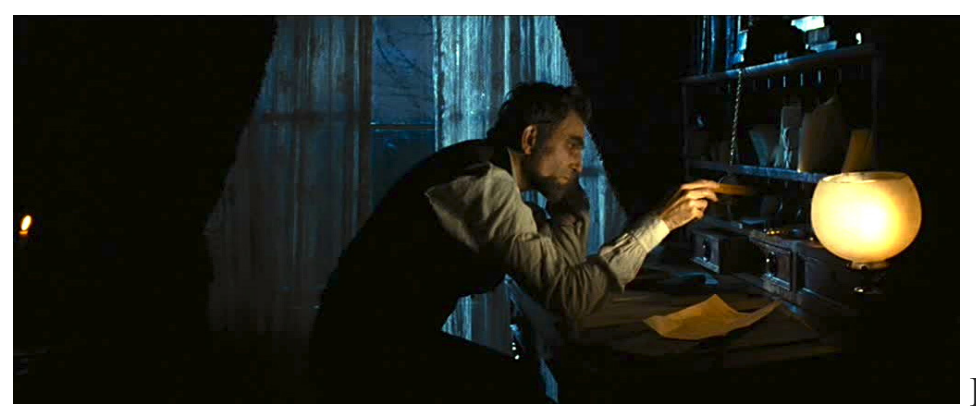

F20

\section{Síntesis y conclusiones finales}

La palabra, su uso y su presencia, constituyen el eje principal que recorre los cuatro entornos en los que se cifran las masculinidaes representadas por Daniel Day-Lewis en su interpretación de Abraham Lincoln, apoyado por la dirección de Spielberg y del resto del equipo que ha creado este texto fílmico.

La palabra nos remite al fantasma del presidente: lo antecede antes de que lo veamos, y se le sigue oyendo cuando Lincoln ha fallecido. En diversos momentos de la película la palabra se usa en lugar de la acción, bien sea para explicarla, para proporcionar una lista o simplemente para nombrarla. La palabra constituye el arma más poderosa en las escenas que el presidente comparte con su esposa o con sus hijos, y se convierte en el mejor útil que puede esgrimir cuando se trata de convencer a sus compañeros y a sus enemigos políticos. 
El silencio, o mejor dicho, la ausencia de la palabra, nos acerca al Lincoln más íntimo, al que es capaz de escuchar la cadencia de la Historia en el devenir de los tiempos. Palabras son las que forman la Decimotercer Enmienda y las alocuciones del presidente. Cuando la película se cierra y dejamos de oír esa voz, Spielberg introduce la suya propia y rubrica su obra como director.

\section{Referencias bibliográficas}

A. MUÑOZ, A. (1999). "Emoticones". Vivat Academia, no 5, Madrid: Fórum Internacional de Comunicación y Relaciones Públicas - FÓRUM XXI. p. 1-10. http:// www.vivatacademia.net/h/anteriores/cinco/Num5/PDFs/Emoticones.pdf

BRUFAO GARCÍA, P. (1997). "José Martí, entorno histórico". Revista de la SEECI, $\mathrm{n}^{\circ}$ 0, Madrid: UCM. p. 47-56. http://www.seeci.net/revista/hemeroteca/Numeros/ Numero\%200/n0-5.pdf [04-11-2013].

BUCKLAND, W. (2006). Directed by Steven Spielberg: Poetics of the Contemporary Blockbuster. Nueva York y Londres: Continuum.

CALDEVILLA DOMÍNGUEZ, D. (2005). El sello Spielberg. Madrid: Editorial Vision Net.

DÍAZ-CUESTA, J. (2010). Hombres de Steven Spielberg. Un análisis de las representaciones de masculinidades en los textos filmicos Duel, Jaws, Jurassic Park, The Lost World: Jurassic Park $y$ War of the Worlds. Logroño: Servicio de Publicaciones de la Universidad de La Rioja.

(2012). "Los hombres de Steven Spielberg en sus películas de monstruos". En Estudios sobre el Mensaje Periodístico, vol. 18, $\mathrm{n}^{\mathrm{o}}$ especial octubre, Madrid: UCM. p. 273-281.

FRIEDMAN, L. D. 2006. Citizen Spielberg. Urbana y Chicago: University of Illinois Press.

GAMERO ESPARZA, C. (2006). "Esclavitud de por acá, la de évano y la de los otros, y la historia paralela. Segunda Parte: Años 1825 d.C. - 2006 d.C.". Vivat Academia $\mathrm{n}^{\mathrm{o}}$ 81, Madrid: Fórum Internacional de Comunicación y Relaciones Públicas - FÓRUM XXI. p. 1-118. http://www.vivatacademia.net/h/anteriores/ n81/Num81/PDFs/n81-1.pdf [04-11-2013].

GORDON, A. M. (2008). Empire of Dreams: The Science Fiction and Fantasy Films of Steven Spielberg. Lanham, Maryland: Rowman \& Littlefield Publisher.

KIRKHAM, P., y THUMIM, J. (ed.) (1993). You Tarzan: Masculinity, Movies and Men. Londres: Lawrence and Wishart.

KOWALSKI, D. A. (2008). Steven Spielberg and Philosophy: We're Gonna Need a Bigger Book. Kentucky: The University Press of Kentucky.

LOSHITZKY, Y. (1997). Spielberg's Holocaust: Critical Perspectives on Schindler's List. Bloomington: Indiana University Press.

MORRIS, N. (2007). The Cinema of Steven Spielberg. Empire of Light. Londres: Wallflower Press.

SÁNCHEZ-ESCALONILLA, A. (1995). Steven Spielberg. Barcelona: Royal Books. 
(2004). Steven Spielberg: Entre Ulises y Peter Pan. Madrid: Cie Dossat 2000.

SCHICKEL, Richard (2012). Spielberg: A Retrospective. Londres: Thames \& Hudson.

SILET, C. L. P. (2002). The Films of Steven Spielberg: Critical Essays. Lanham, Maryland y Oxford: Scarecrow Press.

TORRES-HORTELANO, L. J. (2011). "De lo vernacular y el World Cinema en Biutiful'. Revista de la SEECI, no 24, Madrid: UCM. p. 50-68. http://www.seeci. net/revista/hemeroteca/Numeros/Numero\%2024/Lorenzo.pdf [04-11-2013].

WASSER, F. (2010). Steven Spielberg's America. Cambridge y Malden, Massachusetts: Polity Press.

Páginas web

http://www.imdb.com/name/nm0000358/bio?ref_=nm_ov_bio_sm [04-11-2013].

\section{Notas}

1 Parte de la investigación para este artículo fue financiada por el proyecto de la Universidad de la Rioja denominado GENEID, de referencia PROFAI13/21, subvencionado por el Banco Santander.

2 Véase la entrada para este actor en la base de datos IMDB: http://www.imdb.com/name/nm0000358/ bio?ref_=nm_ov_bio_sm.

3 Ibid.

4 Con la letra minúscula se indica que se trata de una misma toma de la que proceden esos fotogramas.

5 La XIII Enmienda abrirá el camino de otras aboliciones de esclavitudes en el resto de América: Como Lincoln en la década de 1860, los generales San Martín y Bolívar hicieron un llamado a la abolición como una táctica militar. Los hombres negros se unieron a las filas de los movimientos independentistas para avanzar la emancipación general. (Gamero Esparza, 2006: 103)

\section{El autor}

José Díaz-Cuesta es Profesor Contratado Doctor del área de Filología Inglesa en la Universidad de La Rioja (España), y Responsable de la Unidad de Audiovisuales de la Facultad de Letras y de la Educación de esta institución. Su investigación se centra en el estudio de las representaciones de masculinidades en textos literarios y fílmicos de autores anglo-norteamericanos, así como en las relaciones que se establecen entre ambos tipos de textos. Es autor de la monografía Hombres de Steven Spielberg (2010), y ha editado, junto con Paula Requeijo Rey, el libro Innovar en el EEES a través de la investigación (2012). 